\title{
Correction to: Over half of seniors who start oral bisphosphonate therapy are exposed for 3 or more years: novel rolling window approach and patterns of use
}

\author{
Editorial Office of Osteoporosis International
}

Published online: 24 February 2021

(C) International Osteoporosis Foundation and National Osteoporosis Foundation 2021

\section{Correction to: Osteoporosis International}

https://doi.org/10.1007/s00198-020-05794-2

The original version of this article, published on 07 January 2021, unfortunately contained a mistake. The wrong file was uploaded in the Supplementary information.

The original article has been corrected.

Publisher's note Springer Nature remains neutral with regard to jurisdictional claims in published maps and institutional affiliations.

The online version of the original article can be found at https://oi.org/ 10.1007/s00198-020-05794-2

\section{Editorial Office of Osteoporosis International}

https://www.springer.com/journal/198 